\section{A generalized nonparametric ANOVA program (Version 2)}

\author{
JAMES J. ROBERGE \\ Temple University, Philadelphia, Pennsylvania 19122
}

and

\section{JAMES ROBERGE \\ Northwestern University, Evanston, Illinois 60201}

The program discussed in this paper is designed to (1) compute various nonparametric ANOVA statistics (Cochran, 1950; Friedman, 1937; Kruskal \& Wallis, 1952), (2) compare the value of a given statistic with the chi-square values required for significance at the .05 and .01 levels, (3) perform a priori or post hoc trend analyses (Ferguson, 1965, 1971; Marascuilo \& McSweeney, 1967), and (4) carry out post hoc multiple comparisons (Dunn, 1964; Rosenthal \& Ferguson, 1965; Nemenyi, Note 1).

Input. The job deck consists of some subset of the following cards (depending upon the analyses requested by the user: problem card, contrast matrix format card, contrast matrix card(s), levels format card, levels card(s), data format card, sample size card(s), data deck, and last card. The problem card indicates the nonparametric ANOVA test desired, the number of samples (or experimental conditions), and the specific a priori or post hoc analyses to be performed. If post hoc comparisons (other than all pairwise comparisons) are desired, the contrast matrix format card is an F-type variable format card that indicates the location of the coefficients for the comparisons on the subsequent contrast matrix card(s). Similarly, if a post hoc trend analysis is desired, the levels format card (for unequal intervals) is an F-type variable format card that indicates the location of the level magnitudes on the accompanying levels card(s); for equal intervals, the levels format card and levels card(s) are omitted. The data format card is an F-type variable format card that indicates the location of the raw scores (or ranks) on the data cards. It is followed by a card (or cards) indicating the size(s) of the sample(s). The arrangement of the data deck varies according to the specific nonparametric ANOVA that is to be performed. Specifically, for the Kruskal-Wallis test, the data are punched by sample with the data for each sample beginning on a new card. However, for the Friedman test and the Cochran test, the data are punched by subject (or group of matched subjects) with the data for each subject (or group of matched subjects) beginning on a new card. Finally, if the user wishes to terminate the program, the last card must have the word FINISH punched in columns 1-6. On the other hand, if the user wishes to analyze another set of data, the last card is a blank card and the job deck is arranged sequentially (as described above) beginning with the problem card.

Output. The output depends upon the options that the user chooses. It is described in detail in various papers (Roberge, 1970, 1971a, b, 1972).

Computer and Language. The program is written in FORTRAN IV for processing by computers in the IBM 360 (or the CDC 6000) series. Well documented, it has variable names that are mnemonic and correspond to the symbols used in behavioral science statistics books, to facilitate modification by users.

Restrictions. The program has the following limitations: (1) There can be a maximum of 30 samples (or experimental conditions), (2) each sample (or experimental condition) can have a maximum of 200 subjects, and (3) if a post hoc trend analysis is desired, there must be an equal number of subjects in each sample (or experimental condition).

Availability. Copies of this paper, test data, and a source listing which includes sample output may be obtained without charge by writing to James J. Roberge, Temple University, Department of Educational Psychology, Philadelphia, Pennsylvania 19122.

\section{REFERENCE NOTE}

1. Nemenyi, P. B. Distribution-free multiple comparisons. Unpublished doctoral dissertation, Princeton University, 1963.

\section{REFERENCES}

CoCHRAN, W. G. The comparison of percentages in matched samples. Biometrika, 1950, 37, 256-266.

DunN, O. J. Multiple comparisons using rank sums. Technometrics, 1964, 6, 241-252.

Ferguson, G. A. Nonparametric trend analysis. Montreal: McGill University Press, 1965.

Ferguson, G. A. Statistical analysis in psychology and education (3rd ed.). New York: McGraw-Hill, 1971.

Friedman, M. The use of ranks to avoid the assumption of normality implicit in the analysis of variance. Journal of the American Statistical Association, 1937, 32, 675-701.

Kruskal, W. H., \& W WLlis, W. A. Use of ranks in one criterion variance analysis. Journal of the American Statistical Association, 1952, 47, 583-621.

Marascuilo, L. A., \& McSweeney, M. Nonparametric post hoc comparisons for trend. Psychological Bulletin, 1967, 67, 401-412.

RoBERGE, J, J. A computer program for nonparametric analyses of variance. Educational and Psychological Measurement, 1970, 30, 731-733.

Roberge, J. J. A computer program for nonparametric post hoc comparisons for trend. Educational and Psychological Measurement, 1971, 31, 275-278. (a)

RoBERGE, J. J. A computer program for nonparametric post hoc multiple comparisons. Educational and Psychological Measurement, 1971, 31, 755-760. (b)

RoBerge, J. J. A computer program for nonparametric tests of ordered hypotheses. Educational and Psychological Measurement, 1972, 32, 157-160.

Rosenthal, I., \& FERguson, T. S. An asymptotically distribution-free multiple comparison method with application to the problem of $\mathrm{n}$ rankings of $\mathrm{m}$ objects. British Journal of Mathematical and Statistical Psychology, 1965, 18, 243-254. 